\title{
ANÁLISE DAS CONCEPÇÕES DE APRENDIZAGEM DE UMA ALFABETIZADORA BEM-SUCEDIDA
}

\author{
ELISABETE REGINA DO CARMO \\ Especialista em Alfabetização pela Fundação de Ensino Superior de São João del-Rei \\ lisacarmo@hotmail.com \\ ENEIDA MARIA CHAVES \\ Graduate School/Indiana University - USA. Departamento de Ciências \\ da Educação da Fundação de Ensino Superior de São João del-Rei. \\ Coord. visitante do Mestrado Interinstitucional em Educação da PUC-RJ e Funrei/Capes \\ echaves@funrei.br
}

\section{RESUMO}

Este artigo pretende apresentar os resultados da análise das concepções de aprendizagem construídas por uma alfabetizadora da rede pública, durante sua formação acadêmica e sua prática pedagógica. Utilizando abordagem etnográfica, dados foram levantados mediante observações em sala de aula (e seus respectivos diários de campos), entrevistas gravadas, relatórios e anotações pessoais da docente. Chegou-se à conclusão de que essa alfabetizadora fundamentou suas práticas em teorias diversas, principalmente em pressupostos psicogenéticos, mas apoiou-se também em alguns aspectos básicos do Behaviorismo e do Humanismo, postura que Ihe possibilitou ter uma prática bem-sucedida.

FORMAÇÃODEPROFESSORES-ALFABETIZAÇÃO-PRÁTICADOCENTE-APRENDIZAGEM

\section{ABSTRACT}

ANALYSIS OF THE LEARNING CONCEPTS OF A SUCCESSFUL LITERACY TRAINER. The aim of this article is to present the results of the analysis of the learning concepts built by a public school teacher, throughout her academic preparation and her pedagogical practices. Using an ethnographic approach, the data were collected through observation of routine classroom practices (and their respective field diaries), recorded interviews and the teacher's own written reports. The results of the analysis suggested that this teacher has based her daily practices on genetic foundations, but she has also searched for behaviorist and humanist concepts which allowed her to have an effective practice. 


\section{OBJETIVOS E METODOLOGIA}

Este artigo tem como objetivo analisar as concepções de aprendizagem de uma alfabetizadora considerada bem-sucedida por todos que conhecem sua atuação: colegas de profissão, pais de alunos e avaliadores de um concurso nacional' . A partir de dados levantados no seu cotidiano escolar, pretendeu-se também verificar a inter-relação de saberes teóricos e saberes construídos ao longo de sua prática como educadora.

A partir da década de 80, a pesquisa educacional começou a voltar a sua atenção para as práticas pedagógicas e para a pessoa do professor na tentativa de unir sua identidade, de forma que o docente como profissional não estivesse separado do docente como pessoa. Em contraposição à tendência anterior que reduzia "a profissão docente a um conjunto de competências e de capacidades, realçando essencialmente a dimensão técnica da ação pedagógica" (Nóvoa, 1992, p. I5), o professor passou a ser considerado o ator em todas as mudanças pelas quais a educação passa.

Construir uma prática pedagógica que consiga atender hoje a todas as demandas do sistema educacional implica a instrumentalização teórico-prática do profissional da educação, possibilitando-lhe ultrapassar a burocracia institucional e governamental e responder ao seu papel que é continuamente construído e desconstruído socialmente. Mudanças sociais fizeram com que a escola assumisse tarefas e limites que antes cabiam à família, o que veio ampliar as exigências com o professorado em suas práticas cotidianas, tornando-se necessário trabalhar a afetividade, a interação grupal e social, a orientação sexual e moral, e, também, zelar pelo equilíbrio psicológico.

Conseqüentemente, conseguir entender a construção do saber docente com toda a sua multiplicidade de características é um passo importante na tentativa de uma melhora qualitativa em nosso sistema educacional e na compreensão das relações que acontecem dentro da escola (Canto, 1998). Além disso, para que os docentes consigam exercer sua profissão conscientes da importância de seu papel social e seguros do conhecimento que estão manuseando, Nóvoa (1995) enfatiza ser necessário que "se apropriem dos saberes de que são portadores e os trabaIhem do ponto de vista teórico e conceptual" (p. I7).

I. A profissional, cujas concepções de aprendizagem serão analisadas neste trabalho, recebeu um prêmio nacional da Fundação Victor Civita como "Alfabetizadora Nota I0". 
Como, em sua maioria, as pesquisas estão preocupadas em definir e mostrar os principais entraves da relação do docente com o seu saber (Canto, 1998; Giesta, 1996; Caldeira, 1995; Pimenta, 1996; Therrien, 1993), escolhemos focalizar uma experiência positiva, concordando com Dias-da-Silva (1994), que afirma:

Ao ressaltar os caminhos possíveis e efetivamente realizáveis, no contexto da escola pública brasileira hoje, abrem-se perspectivas de transformação, posição contrária à pesquisa tradicional, que, ao questionar as características negativas do trabalho pedagógico, apenas evoca o que não deve ser feito, sem contudo apontar saídas. (p.40)

Relatar um caso de experiência bem-sucedida de docência, e especificamente analisar as concepções de aprendizagem que norteiam o fazer pedagógico da docente investigada, além de apontar caminhos para outras práticas, vem resgatar o papel estratégico que o professor ocupa na sociedade.

Os dados a serem analisados neste artigo foram coletados mediante observações, entrevistas gravadas e relatórios confeccionados pela própria docente. Iniciaremos caracterizando o sujeito e percorrendo sua história de vida pessoal e profissional.

\section{APRESENTAÇÃO DO AMBIENTE E DO SUJEITO INVESTIGADOS}

As observações de um caso de prática bem-sucedida deram-se dentro do contexto de uma escola do estado de ensino fundamental na cidade de São João del-Rei, em duas situações distintas: primeiramente, numa sala de I a série do $I^{\circ}$ ciclo, com 24 alunos, durante cinco dias consecutivos em outubro de 1998; e posteriormente, durante três semanas em setembro de 1999, numa sala de reforço extraturno, atendendo a três grupos com uma média de oito alunos. As salas de aula eram bastante confortáveis, abastecidas de luz natural, bem arejadas. As carteiras eram formadas por cadeiras e mesinhas, dispostas em grupo de quatro ou de dois alunos. A mesa da professora ficava no canto esquerdo da sala e ao lado havia um espaço reservado para a realização da "rodinha" (atividade diária em que as crianças e docente sentavam-se no chão em círculo para conversarem). As paredes de cor clara sustentavam flanelógrafos e produções coletivas e individuais das crianças, bem como cartazes e painéis. As salas contavam ainda com um Cantinho de Leitura e alguns materiais didáticos, como lápis de cor, giz, lápis preto, algumas cartilhas, cola, tesoura, entre outros, para uso das crianças. As atividades de recuperação aconteciam numa sala onde havia jogos pedagógicos, teatro de marionetes e almofadinhas à disposição dos professores e dos alunos. 
Em relação à docente investigada, que de agora em diante designaremos pelo pseudônimo Margarida, chamou-nos a atenção o motivo que a fez escolher o magistério: o gosto por essa profissão e a certeza de que esta era a sua vocação, conforme explicita em entrevista gravada:

Eu acredito no trabalho que eu faço, eu gosto do que eu faço, porque, às vezes, as pessoas estão professoras, mas não são professoras por vontade só, porque é a oportunidade. No meu caso, não. Desde pequenina, eu brincava era de professora. Tanto é que eu sou a ovelha desgarrada lá de casa: ninguém foi para a área da educação. Eu sou a mais nova, meus irmãos se formaram em contabilidade, fizeram economia. Dos três, eu fui a única que foi para o lado da pedagogia e a princípio contra a vontade do papai que achava que professora não dava nada. Não é por aí; eu vejo hoje em dia que, de todos nós lá de casa, eu sou a mais realizada, a que me encontro mais. (...) Na realidade, então, acho que a coisa veio inata: desde pequenininha, era o que eu queria fazer. Fiz o curso, me encontrei, me saí bem. Porque, às vezes, você tem aquele sonho e não se realiza, mas eu tive a sorte de realizá-lo. (Grifos nossos)

Por esse depoimento, é possível verificar a ligação que a professora Margarida faz entre a profissão e a realização pessoal, confirmando o que dizem vários teóricos que quanto mais uma pessoa gostar de seu trabalho, maior será sua satisfação pessoal e maior será seu empenho para realizá-lo da melhor maneira possível. Ao dizer que "se encontra na profissão", indica o quanto está envolvida na docência ao ponto de se refletir e se identificar como pessoa quando está trabaIhando.

Sua trajetória profissional é bastante rica: tem atuado em diferentes funções, acumulando experiências que possibilitaram também seu aperfeiçoamento. Formada em magistério em 1981, trabalhou logo depois de formada, no primeiro semestre de 1982, como secretária em um colégio particular, iniciando já no segundo semestre sua carreira como docente na pré-escola; lecionava segundo os moldes tradicionais, mas vislumbrava possibilidades de crescimento e de mudanças, como confirma a fala abaixo:

Na época, eu alfabetizava - na época em que a pré-escola alfabetizava. Alfabetizei com cartilha, com o Davi. Eu tive todas as experiências, mas foi algo que cresceu, tornou-se uma prática que se construiu. E eu acho que a gente cresce é dessa forma. (Entrevista gravada)

Um pouco depois, ingressou no curso de pedagogia, buscando sempre seu aperfeiçoamento profissional e procurando fundamentação teórica para a sua prá- 
tica pedagógica, como esclarece: "Eu não parei no tempo e no espaço, eu achei que este era o caminho, que era aí que eu ia ficar. Então, foi aí que eu procurei me especializar e encontrar mais subsídios para a minha prática" (entrevista gravada). Em 1988, já formada, começou atividades também como pedagoga, mas nunca se distanciou da sala de aula. Desde então, até o momento, tem atuado como especialista em supervisão escolar em vários tipos de escolas em São João del-Rei e em cidades circunvizinhas, desde as de linha mais tradicional até aquelas com uma abertura maior. Em todas elas, tem tido oportunidades de introduzir idéias inovadoras e desenvolver um trabalho versátil, abrindo novos espaços para professores poderem colocar suas dúvidas profissionais e trocar suas experiências. Poder trabalhar como supervisora pedagógica e ao mesmo tempo como docente proporciona intercâmbio da teoria e prática, situação em que procura socializar os conhecimentos até então construídos, como indica no depoimento abaixo:

Eu fui repensando no momento em que orientava professoras, porque fui supervisora muitos anos da alfabetização. Eu colocava naquela orientação um pouco da minha prática em sala de aula, porque acho isso fundamental. Deve ser muito difícil orientarmos alguém sem conhecer a prática, só baseados em teoria. (Entrevista gravada)

Trabalhou ainda na suplência com alfabetização de adultos à noite, experiência que qualifica como "altamente rica", enquanto, durante o dia, exercia o cargo de assessora pedagógica na $34^{\mathrm{a}}$ Superintendência Regional de Ensino (34 $\left.{ }^{\mathrm{a}} \mathrm{SRE}\right)$. Essa prática de desempenhar atividades profissionais em mais de um horário é uma constante na vida da docente observada que desabafa: “... eu sempre trabaIhei demais. (...) Nunca fiquei trabalhando em um horário só, sempre conciliando dois horários e até três" (entrevista gravada, grifos nossos). Uma análise rápida da realidade social da docência no Brasil mostra que aos profissionais da educação são impostas jornadas duplas de trabalho para que possam sobreviver com condições mínimas. Muitas vezes, essa realidade justifica certa insatisfação e trabalhos descomprometidos com a educação.

Conforme nos aponta a professora Margarida, o caminho é conciliar a teoria com a experiência acumulada no decorrer da vida profissional, adicionando, ainda, o acreditar no que está fazendo com o gostar e com uma dose grande de responsabilidade:

E eu tentava partir do seguinte princípio: se eu assumi, eu tenho que dar conta e dar conta bem-feito, porque um trabalho não tem a ver com o outro; então, não 
posso deixar de lado alguma coisa, porque eu assumi outra. Tenho que dar conta de tudo. (Entrevista gravada)

Essa postura assertiva da professora é sustentada por uma excelente organização do trabalho pedagógico; nos finais de semana, a docente planeja todas as atividades a serem desenvolvidas durante a semana. Esse comprometimento com o seu trabalho é visível tanto na prática cotidiana quanto é verificável em sua fala:

Para isso, eu quase me mato para dar conta de casa, ser mãe, ser dona de casa. E eu não tenho empregada, tenho uma faxineira! Mas eu acho que, por gostar, por ter esse senso de responsabilidade muito acirrado, porque eu tenho, eu exijo muito de mim. Aí, a coisa tem de funcionar. (Entrevista gravada)

Outra experiência significativa foi um trabalho desenvolvido por quatro anos na Associação de Pais e Amigos dos Excepcionais - Apae - na qual, mais uma vez, atuava concomitantemente como especialista e como docente. Nessa mesma época, porque ingressou no curso de pós-graduação em alfabetização, continuou somente com a condução do processo de leitura e escrita de crianças com dificuldades diferenciadas de aprendizagem. Esse tipo de atuação docente possibilitou-lhe um trabalho de campo muito profícuo, indicando os caminhos da elaboração de sua monografia de final de curso, oportunidade de conciliar teoria e prática.

Em agosto de 1995, logo que terminou o curso de pós-graduação, recebeu um convite para coordenar a divisão de acompanhamento pedagógico da $34^{\mathrm{a}}$ SRE. Dos projetos aí desenvolvidos, destaca-se o chamado Revitalização do CBA, que envolveu todos os municípios ligados a essa superintendência. Uma vez por mês, sob a orientação da docente, reuniam-se cerca de 250 alfabetizadores durante oito horas para uma atualização sobre processos de aquisição da leitura e da escrita, conforme nos informa:

A gente trabalhava nesses encontros as dificuldades que as professoras apresentavam, mas a respeito do que vi na pós. Olha que oportunidade que tive de socializar tudo aquilo que nós vimos nesse curso! Foi, assim, um trabalho que ficou muito bom. (Entrevista gravada)

Por esse depoimento, fica claro que essa docente tem plena consciência de suas competências e tem senso crítico que lhe possibilita reflexões sobre suas próprias ações (Schön, 1992).

Em setembro de 1996, depois de ter passado em um concurso público, atuou como professora substituta de Didática, Estrutura e Funcionamento do Ensi- 
no e Estágio Supervisionado para alunos de cursos superiores da Fundação de Ensino Superior de São João del-Rei - Funrei. Por isso, deixou o cargo na Superintendência, ainda que estivesse consciente das desvantagens financeiras, pois acreditava que essa nova experiência seria enriquecedora para sua trajetória profissional e lhe daria oportunidades de também socializar conhecimentos teóricos adquiridos no curso de pós-graduação.

Com essa apresentação da história profissional da professora investigada, ao longo do seu período de formação e da sua prática, pretendemos antecipar o seu processo gradativo de construção teórico-prática que lhe possibilitou desenvolver atividades docentes consideradas bem-sucedidas.

\section{APRESENTAÇÃO E ANÁLISE DE DADOS}

Mediante análise global dos dados, é possível verificar que as práticas pedagógicas investigadas sofrem forte influência das teorias psicogenéticas, mostrando marca acentuadamente construtivista. No entanto, a própria docente Margarida deixa claro que recorre a toda e qualquer teoria que possa auxiliá-la na construção de um saber prático necessário à sua atuação cotidiana, inclusive alguns pressupostos básicos do behaviorismo, principalmente pelo reforço positivo, e pelo humanismo, expresso no respeito pela fala dos alunos e por suas realidades de vida, como se ilustra a seguir:

Eu acredito que isso tudo [o desenvolvimento global dos alunos] foi possível por causa do clima de respeito à fala do outro e do espírito de solidariedade que os grupos conseguiram estabelecer. Discutimos os casos de filhos de mães solteiras, a realidade de crianças sem pais ou com pais separados, a chegada de um nenê na família, as próprias dificuldades financeiras, os casos de pais desempregados... Chegamos até a discutir as dificuldades de aprendizagem de algumas crianças. (Entrevista gravada)

Construiu, assim, concepções de aprendizagem que lhe possibilitam ter uma prática muito eficaz no processo de ensino e aprendizagem, partindo de pressupostos fundamentalmente construtivistas, pautando-se nas teorias de Piaget e Emilia Ferreiro.

Piaget começou a investigar os processos internos de construção do conhecimento humano, buscando a sua gênese e investigando as manifestações, reações e comportamentos do indivíduo diante de situações contextuais desde o seu nascimento. Explicitou a lógica do funcionamento mental da criança, mediante concei- 
tos básicos de esquema, assimilação, acomodação e equilibração, indicando como e por que o desenvolvimento cognitivo da criança ocorre. Influenciada pela teoria piagetiana, Emilia Ferreiro investigou a gênese da aquisição da escrita, considerando que as primeiras noções têm seu início antes da entrada das crianças na escola. É comum encontrarmos na teoria de Ferreiro a expressão lecto-escrita, colocando a leitura e a escrita como um mesmo objeto, numa indicação explícita de que sua principal preocupação é com um sujeito cognoscente e sua relação com o conhecimento.

A análise dos dados colhidos nas observações mostra que a alfabetizadora investigada adota muitos conceitos de Ferreiro. Uma das marcas que mais se destaca é o uso do termo lecto-escrita, como pode ser comprovado pelos trechos retirados de seus relatórios pessoais:

Realizei então uma sondagem de lecto-escrita que confirmou este diagnóstico inicial; utilizei, para os diferentes grupos de trabalho, propostas diversificadas de atividades escritas, a partir de jogos de lecto-escrita.

Outro exemplo claro está impresso nos relatórios do projeto de reforço extraturno em que se propõe desenvolver atividades com crianças com dificuldades de aprendizagem. As anotações da professora indicam que faz, nesses momentos, uma "sondagem de lecto-escrita" e avalia os conhecimentos prévios das crianças, dividindo-as em grupos distintos de acordo com a concepção que cada uma trazia da leitura e da escrita.

Para Ferreiro (1987, 1990), a aquisição da escrita passa por uma evolução compreendendo diversas etapas que se interligam indicando os níveis de conceitualização em que uma criança se encontra. Identifica três períodos nessa evolução. O primeiro período, segundo a autora, é marcado pela diferenciação da criança entre o desenhar e o escrever. No início, as letras são objetos que possuem nomes, não tendo ainda o caráter de objetos substitutos; nesse momento, as crianças buscam relacionar os textos com figuras próximas. Começa, então, uma fase na qual uma palavra só é interpretada se tiver uma quantidade mínima de letras (que podem ser na verdade algarismos, pseudoletras, bolinhas ou barras) e se estas não forem repetidas, inicia-se, a partir daí, o segundo período.

No segundo período, permanecem e acentuam-se as condições de interpretabilidade de um texto: o critério de variação intrafigural e o mínimo de três letras para que uma palavra possa ser lida. A criança começa a tentar criar diferenças nos textos para poder representar coisas diferentes sob dois eixos principais: o qualitativo, no qual a criança varia as letras e a sua posição nas respectivas palavras, 
e o quantitativo, no qual a criança varia a quantidade de letras para representar palavras diferentes ou o aumentativo e o diminutivo das palavras. Nesses dois períodos, a criança não regulamenta a escrita por significantes sonoros. É a partir do terceiro período que nasce a idéia de fonetização da escrita quando a hipótese silábica emerge:

Esta hipótese silábica é da maior importância, por duas razões: permite obter um critério geral para regular as variações na quantidade de letras que devem ser escritas, e centra a atenção da criança nas variações sonoras entre as palavras. (Ferreiro, 1987, p.25)

Nesse período silábico, as crianças começam a vivenciar conflitos derivados de contradições com a hipótese do número mínimo de letras e a existência dos monossílabos, por exemplo, e a contradição com a interpretação que os adultos dão às palavras com mais letras do que eles julgam necessário para as palavras. Mas é também nesse período que as crianças começam a estabilizar os valores sonoros e a corresponder as partes com som semelhantes e letras semelhantes.

Esses conflitos acabam por desestabilizar a criança, levando-a ao período silábico-alfabético, momento em que "a criança descobre que a sílaba não pode ser considerada como uma unidade, mas que ela é, por sua vez, reanalisável em elementos menores, ingressa no último passo da compreensão do sistema socialmente estabelecido" (Ferreiro, 1987, p.27).

A análise dos dados colhidos nas observações da docente Margarida mostra que esta buscava, a todo momento, valorizar as ações das crianças, considerando-as construtoras de seu conhecimento, e não apenas meras receptoras, postura que lhe possibilitou trabalhar conteúdos trazidos de casa. E enquanto levava em consideração os conhecimentos prévios e os contextos sociais das crianças, estava permitindo que elas significassem seus aprendizados. Com isso, é possível entender por que a professora observada, assim como outros adeptos da teoria construtivista, parte do nome da criança ou de textos que tenham significado para elas ao se iniciar o processo de ensino e aprendizagem da leitura e da escrita. Trabalhando com textos significativos não se ignora aquilo que a criança traz consigo, aspecto que fica evidente na fala de Margarida: "O meu objetivo, o objetivo principal era alfabetizar meus alunos, a partir de suas realidades e dentro de um contexto significativo para eles" (entrevista gravada). A sala de aula observada evidencia essa preocupação, pois em suas paredes encontravam-se vários cartazes com produções coletivas, construídas primeiro oralmente antes de passarem para um registro escrito, cujos temas remetiam às vivências 
das crianças, como por exemplo, a descrição dos colegas de sala de aula. Posteriormente, os textos eram digitados em letras maiúsculas e expostos na sala de aula para que as crianças lessem sempre que desejassem, valorizando-se não somente a forma, mas também o conteúdo das produções. Um dos cartazes era justamente o da listagem com o nome dos alunos em ordem alfabética, estratégia significativa, pois o nome acompanha o indivíduo desde seu nascimento, marcando a identidade de cada um.

Observou-se um belo trabalho desenvolvido a partir do nome de cada criança trazendo como eixo temático justamente a sua identidade e visando resgatar a auto-estima dos alunos. Esse processo de construção culminou com a confecção de um livro individual sob o título Revelando minha identidade. Por isso, a história de vida de cada um foi pesquisada, reconstruindo-se desde a "história de amor de seus pais", passando pela primeira infância até os dias atuais, como explicita a professora Margarida:

Nós partimos do nome de cada criança pra realização de um trabalho que a coordenação pedagógica propôs. Então, as crianças contaram muitas histórias: contaram quem escolheu o nome delas, os significados dos nomes. Desenvolvemos várias atividades chamando a atenção para os nomes iguais, os nomes mais comuns, para o número de letras, letras iniciais e finais. Trabalhamos com vários jogos envolvendo os nomes... (Entrevista gravada)

Essa postura pedagógica que valoriza a interação entre o sujeito e seu objeto de estudo, tão fundamental no processo ensino-aprendizagem, evidencia a importância depositada na construção histórica que envolve cada aluno.

Outro teórico que trabalha com a importância da interação sujeito-objeto é Vigotski, que integra em uma mesma perspectiva o homem como ser biológico e social participante de um processo histórico. Para esse autor, não é possível pesquisar as pessoas fora de seus contextos socioculturais, pois os fenômenos sociais, semióticos e psicológicos estão dentro do mesmo marco conceitual (Reig, Gradolí, 1998). Nessa perspectiva, observamos que a interação social, tendo como mediadora a linguagem oral, era sempre muito privilegiada pela professora Margarida. Diariamente eram feitas "rodinhas" em que cada criança tinha o seu momento de interagir com o outro, constituindo, durante a realização do trabalho sobre a identidade, espaços de fundamental importância:

Nós fizemos rodinhas diárias de conversas informais, realizamos leituras e as crianças falaram de suas experiências. Essas rodinhas possibilitaram um espaço interessante para as crianças contarem fatos importantes de suas histórias e mostrarem 
suas fotografias. Essas fotografias mostravam várias fases de quando eram bebês até os dias atuais. E a rodinha se tornou o grande centro de interesse e motivação para o trabalho de escrita de um livrinho. (Entrevista gravada)

Durante as observações, notamos também que se dava o máximo de autonomia grupal, favorecendo, assim, a interação social entre os alunos, deixando que estes formulassem suas hipóteses e se ajudassem num primeiro momento sem a intervenção da professora. Foi bastante comum esse movimento em sala de aula: as crianças andavam livremente nos pequenos grupos comparando suas escritas, construindo sua lógica e discutindo entre si. A docente Margarida demonstrou ter consciência de que a autonomia grupal tem como objetivo a independência e o amadurecimento não só do processo de aprendizagem mas da própria formação cognitiva, estimulando-se os aspectos lógicos e racionais da criança bem como de suas personalidades.

A liberdade vivenciada pelos alunos condiz também com os pressupostos da teoria humanista e é tida como condição para o desenvolvimento e a aprendizagem, pois permite ao indivíduo vasto horizonte para pensar, sentir e ser, de forma que desempenhe suas tarefas com espontaneidade e responsabilidade. Por exemplo, um exercício dado em sala de aula pedia que cada grupo escrevesse uma lista de nomes: de animais, flores ou brinquedos (sorteados pelos grupos), em um tempo determinado. $\bigcirc$ grupo que acabasse com o maior número de palavras ganharia um prêmio. $\bigcirc$ movimento das crianças foi impressionante: todos os componentes do grupo ajudavam na construção das palavras, discutiam a grafia, movimentavam-se de forma que houvesse participação total. Ao final do exercício, foi feita uma leitura das palavras, assim como a escrita coletiva no quadro de giz e a sua correção coletiva. $\mathrm{O}(\mathrm{s})$ grupo(s) vencedor(es) receberia(m) lápis como prêmio, mas como não estava em jogo a competição para se saber quem eram "os melhores", excluindo-se os menos bons, mas uma construção coletiva da linguagem escrita, todos ganharam um lápis. Duas coisas ficaram evidentes, além da valorização da autonomia grupal: uma foi o respeito e a valorização da produção das crianças e a outra foi como os grupos que ficaram em segundo e terceiro lugares (em nenhum momento usou-se a palavra perdedores) não se frustraram por não terem ficado em primeiro lugar.

Otrabalho de forma lúdica é preocupação constante da docente Margarida. Várias foram as oportunidades em que presenciamos brincadeiras de roda, músicas, parlendas, teatro de fantoches, competições, entre outros, pois ela acredita que a criança recém-saída da pré-escola sentirá mais tranqüilidade no aprendizado 
se a marca lúdica continuar presente. Na alfabetização, o trabalho com o lúdico é seu grande aliado, como informa no depoimento a seguir:

...porque eu acho que a alfabetização é um momento assim, que precisa ser muito lúdico, eu não vejo, não consigo encarar de outra forma, a minha turma, por exemplo: as minhas turmas, todos que passam por mim vibram com as atividades de competição, de jogos, (...) porque eu não tenho muita dificuldade nisso, tenho facilidade para fazer (...). Porque não adianta uma criança com uma primeira experiência na escola depois da pré-escola, que tem todo aquele aspecto lúdico... acho que é um choque muito grande quando ela chega no curso de $1^{a}$ a $4^{a}$ série e encontra uma rigidez por parte do professor, muito preocupado com o programa, com as famílias silábicas que ele tem que dar conta, que os alunos têm de ler e escrever. (Entrevista gravada)

Os conteúdos eram previamente planejados pela professora, mas, resolvidas as propostas, iam sendo criadas situações que levavam os alunos a investigarem outras possíveis soluções e a fazerem novas descobertas. Realizava, assim, um trabalho interdisciplinar que, além de flexível, mostrou-se muito produtivo, como relata sobre as atividades em torno do tema identidade:

O nosso trabalho com o tema identidade possibilitou o desenvolvimento de muitas atividades de pesquisa, leitura, produção de texto, relatos orais, durante todo o ano. Na verdade, trabalhei com uma abordagem interdisciplinar, a partir da realidade de vida de cada criança. O resultado final mais importante foi a construção do primeiro livrinho com o título: Revelando minha identidade. (Entrevista gravada)

Um outro exemplo dessa flexibilidade se deu durante a observação de uma aula para os alunos do reforço extraturno, quando um menino pediu licença para distribuir drops da marca Garoto, para seus colegas. A docente, percebendo a tentativa de burlar a aula, com muita simpatia sugeriu: "Eu tenho uma idéia: que tal se nós deixássemos o drops para o final da aula? Pois, assim, poderemos utilizá-lo para um desafio de matemática. Você se importa?" (Diário de campo). Nesse momento, pudemos perceber algumas reações: primeiro, o desafio de matemática era uma atividade conhecida dos alunos e muito apreciada, pois todos vibraram com um entusiasmo contagiante; a segunda reação foi a do menino que se sentiu tão importante em poder contribuir para o desenvolvimento das atividades que logo voltou aos trabalhos para terminar as tarefas e poder realizar o desafio. Ao final da aula, todos (a professora, os alunos em número de oito e a observadora) se dispuseram ao redor de uma carteira. A professora pegou o drops e perguntou 
o que estava escrito e as crianças responderam em coro: "hortelã". Em seguida, aproveitou para trabalhar a letra $\mathrm{H}$. Depois, perguntou se era possível saber quantos drops existiam dentro do tablete sem abri-lo. As crianças procuraram e acharam a inscrição: "contém dez pastilhas". Mesmo assim, sugeriu que se abrisse o tablete para conferir se a informação estava correta; em seguida, pediu que fizessem a divisão das pastilhas pelo número de participantes. Como havia exatamente dez pessoas na sala, imediatamente as crianças concluíram que cada pessoa receberia um drops. Ainda assim, a docente hipotetizou outras divisões caso houvesse mais e menos pessoas na sala; os alunos optaram por não fazerem divisões complicadas e sugeriram que alguém dividisse seu drops ou que algum ficasse com mais de um. Suas respostas espirituosas foram parabenizadas pela professora em forma de uma grande risada.

A valorização para os avanços pessoais também foi característica marcante na prática observada. Era comum escutarmos palavras de incentivo aos alunos, como: "Parabéns, que delícia, como você está lendo bem!"; "Que coisa boa! Fico feliz de todos terem cumprido a tarefa!"; "Vocês estão craques na leitura e dizem que não sabem!"; "Olhem o desenho de C. como está bonito!" (Diários de campo), e assim por diante.

Como a maior parte das observações se deu em uma sala de 24 alunos, compondo um grupo heterogêneo com níveis diferentes de alfabetização, a professora conseguia explorar as diferenças, fazendo com que estas fossem aliadas e não entraves no processo de ensino e aprendizagem. Um exemplo disso era a formação dos grupos de trabalho em que alunos de níveis diferentes eram colocados na mesma mesa de forma que aqueles mais adiantados mediassem o aprendizado daqueles mais atrasados. Isso era possível devido a uma postura de muito respeito pelas hipóteses das crianças, sem sonegar nenhuma informação essencial para a resolução dos problemas.

Essa interação entre os alunos juntamente com as mediações entre eles e da professora é um grande instrumento no processo de aprendizagem. Segundo Vigotski, existem dois níveis evolutivos: um nível real que indica aquilo que o indivíduo é capaz de fazer sozinho e um nível potencial abrangendo tudo aquilo que o sujeito realiza ajudado ou mediado por outro. A partir desses dois conceitos, Vigotski define o que chama de "zona de desenvolvimento proximal" - ZDP -, que vem a ser a distância entre esses dois níveis de evolução da criança. Em tese, a ZPD é o potencial para uma aprendizagem posterior, mas que já está presente nesse espaço (Reig, Gradolí, 1998). 
Acreditando nesse potencial existente nas crianças, o processo ensino-aprendizagem com uma turma heterogênea se torna possível, uma vez que as diferenças podem ser trabalhadas no grupo. Aqueles alunos que se encontram em um nível inferior podem ser mediados por aqueles mais avançados e seus potenciais estimulados de forma que a aprendizagem se torne concreta.

A professora Margarida apresenta ainda uma postura de escuta e de satisfação diante das indagações das crianças, deixando-as livres e estimuladas a responder e buscar novas questões, ainda que não relacionadas aos conteúdos curriculares. Por exemplo, ao explicar que haveria feriado pelo dia de finados, escuta os alunos que já perderam suas mães, responde a perguntas sobre morte e cemitério com a maior naturalidade possível para o entendimento das crianças.

Apesar de sofrer influências de várias teorias, a marca da influência construtivista é constante, mesmo porque essa é a proposta de trabalho da escola em que a profissional leciona:

Parece que na proposta adotada na escola onde trabalho é uma coisa que parece que vem de dentro, parece passe de mágica, não existe essa preocupação com a família silábica, com o que vai dar conta, e, como que por encanto, começa-se o trabalho tão descontraído, envolvendo tudo, parece até uma retomada do antigo método global: partimos do texto para depois chegar nas partes e com tudo isso, sem uma coisa sistemática preparando, garantindo que ele vai dar conta de ba-bebi-bo-bu, da-de-di-do-du, os meninos estão lendo e escrevendo. (Entrevista gravada, grifos nossos)

Fazendo um parênteses, gostaríamos de esclarecer que destacando o exemplo acima - que o aprendizado parece até uma mágica e não uma coisa formalizada (ba-be-bi-bo-bu, da-de-di-do-du) - não estamos querendo insinuar que a formação silábica seja dispensável para o construtivismo, que considera a produção do conhecimento como "formalizante", mas "não formalizada", porque "nela, forma e conteúdo, ainda que não confundidos, são indissociáveis" (Macedo, 1994, p. I 5).

\section{CONSIDERAÇÕES FINAIS}

Pesquisar um caso de prática docente bem-sucedida trouxe indicadores que podem auxiliar outras práticas alfabetizadoras, bem como mostrou-nos que existem caminhos realizáveis dentro da docência em que o professor tem possibilidades de se apropriar de seus saberes, tanto os de formação quanto os da experiência, formando concepções de aprendizagem que buscam o crescimento pleno dos alunos. 
No caso da alfabetizadora observada, concluímos que possuía concepções de aprendizagem diferenciadas que a auxiliam o tempo todo no desenvolvimento do seu fazer pedagógico, assim como a conduzem a total domínio dos conteúdos a serem trabalhados, conseguindo inseri-los dentro do contexto sociocultural dos alunos. Demonstrou ser capaz de considerar as representações dos discentes e aproveitar seus conhecimentos prévios para desencadear um processo de aprendizagem significativo e sem imposições de um saber inquestionável. Posicionandose como mediadora e facilitadora, utilizou a sala de aula como espaço do qual as crianças, sujeitos ativos, podiam apropriar-se de forma que a construção do conhecimento ocorresse em clima de liberdade e segurança. Valorizava a função social da leitura e da escrita, com uma postura constante de afetividade, ferramenta de trabalho importante no cotidiano escolar.

Em síntese, embora se pautasse em pressupostos psicogenéticos, a professora observada se mostrou aberta para se beneficiar de outras teorias, indicando que a formação teórica ganhou importância em sua vida profissional e lhe possibilitou a aplicação desses conhecimentos em suas práticas cotidianas.

\section{REFERÊNCIAS BIBLIOGRÁFICAS}

CALDEIRA, A. M. S. A Apropriação e construção do saber docente e a prática cotidiana. Cadernos de Pesquisa, n. 95, p. 5-12, nov. 1995.

CANTO, R. S. Teoria, saber docente e formação de professores de ciências. Rio de Janeiro, 1998. Dissert. (mestr.) PUC-Rio.

DANTAS, H. A Afetividade e a construção do sujeito na psicogenética de Wallon. In: LA TAILLE, Y.; OLIVEIRA, M. K.; DANTAS, H. Piaget, Vygotsky, Wallon: teorias psicogenéticas em discussão. São Paulo: Summus, 1992. p. 85-98.

DIAS-DA-SILVA, M. H. G. F. Sabedoria docente: repensando a prática pedagógica. Cadernos de Pesquisa, n. 89, p. 39-47, maio 1994.

FERREIRO, E. A Escrita... antes das letras. In: SINCLAIR, H. (org.). A Produção de notações na criança: linguagem, número, ritmos e melodias. São Paulo: Cortez; Campinas: Autores Associados, 1990. p. 19-70.

Reflexões sobre alfabetização. 2. ed. São Paulo: Cortez; Campinas: Autores Associados, 1987.

Sobre a necessária coordenação entre semelhanças e diferenças. In:

CASTORINA, J. A. et al. Piaget-Vygotsky, novas contribuições para o debate. São Paulo: Ática, 1995. p. 147-75. 
GALVÃO, I. Henri Wallon: uma concepção dialética do desenvolvimento infantil. Petrópolis: Vozes, 1995.

GARCÍA, A.; FABREGAT, A. A Construção humana através da equilibração de estruturas cognitivas: Jean Piaget. In: MINGUET, P. A. (org.). A Construção do conhecimento na educação. Porto Alegre: Artes Médicas, 1998. p. 81-106.

GIESTA, N. C. Profissão docente: construção do próprio saber e de sua identidade. Momento, n. 9, p. 31-7, 1996.

MACEDO, L. Ensaios construtivistas. São Paulo: Casa do Psicólogo, 1994.

NÓVOA, A. Formação de professores e profissão docente. In: NÓVOA, A. (coord.). Os Professores e a sua formação. Lisboa: Dom Quixote, 1992. p. 13-33.

Os Professores e as histórias da sua vida. In: NÓVOA, A. (org.). Vidas de professores. 2. ed. Porto: Porto Editora, 1995. p. II-30.

PIMENTA, S. G. Formação de professores: saberes da docência e identidade do professor. Revista da Faculdade de Educação, v. 22, n. 2, p. 72-89, jul./dez. 1996.

REGO, T. C. Vygotsky. uma perspectiva histórico-cultural da educação. 6. ed. Petrópolis: Vozes, 1998.

REIG, D.; GRADOLÍ, L. A Construção humana através da zona de desenvolvimento potencial: L. S. Vygotsky. In: MINGUET, P. A. (org.). A Construção do conhecimento na educação. Porto Alegre: Artes Médicas, 1998. p. 107-26.

SCHÖN, D. A. Formar professores como profissionais reflexivos. In: NÓVOA, A. (coord.). Os Professores e a sua formação. Lisboa: Dom Quixote, 1992. p. 77-91.

TARDIF, M.; LESSARD, C.; LAHAYE, L. Os Professores face ao saber: esboço de uma problemática do saber docente. Teoria e Educação, n. 4, p. 215-33, 1991.

THERRIEN, J. O Saber social da prática docente. Educação e Sociedade, n. 46, p. 408- I8, dez. 1993.

VYGOTSKY, L. S. Pensamento e linguagem. São Paulo: Martins Fontes, I99I. 